\title{
Making a Community Network Legal within the South African Regulatory Framework
}

\author{
C. Rey-Moreno, W. D. Tucker \\ Computer Science, University of Western Cape \\ Bellville, 7535, South Africa \\ \{crey-moreno,btucker\}@uwc.ac.za
}

\author{
D. Cull, R. Blom \\ Ellipsis Regulatory Solutions \\ Cape Town, 7945, South Africa \\ \{dominic,rolf\}@ellipsis.co.za
}

\begin{abstract}
Community networks often operate at the fringe of legality with respect to spectrum, network infrastructure and providing services. We have been involved with such a network in a rural community, and together with them, have devised a way to become legal within the South African regulatory framework. A not-for-profit co-operative was formed and successfully applied for license exemption to operate the network infrastructure and offer services. Revenue is used to sustain the network and can also be used for other community needs. The network has equipment that is not $100 \%$ type-approved, and operates at a higher output power than is allowed. However, we have a simple plan to comply with such regulations. This paper offers our experience as a precedent for how to go about making a community network completely legal in South Africa and other countries that have a similar regulatory environment.
\end{abstract}

\section{Categories and Subject Descriptors}

Computing/technology policy [Government technology policy]: Governmental Regulations; Network types [Wireless access networks]: Wireless local area networks

\section{INTRODUCTION}

Community networks (CN) are considered to be a potential solution to provide affordable access in rural areas [1], yet people can find it difficult to fit them in the regulatory framework of a country; which may hinder their sustainability [4]. In this paper we describe the process followed to provide a legal CN in rural South Africa.

The CN in Mankosi, a traditional rural community in the Eastern Cape Province of South Africa, has been running for more than 2 years. The $\mathrm{CN}$ started with the goal of reducing the cost of communications in Mankosi [7]. The network is composed of 13 mesh nodes, 11 of which are first generation Mesh Potatoes (TxPower $20 \mathrm{dBm}$ ) with an external antenna attached $(8 \mathrm{dBi})$, creating a mesh network operating in the $2.4 \mathrm{GHz}$ band which covers around $30 \mathrm{~km} 2$. An analogue

Permission to make digital or hard copies of all or part of this work for personal or classroom use is granted without fee provided that copies are not made or distributed for profit or commercial advantage and that copies bear this notice and the full citation on the first page. To copy otherwise, to republish, to post on servers or to redistribute to lists, requires prior specific permission and/or a fee.

Copyright 20XX ACM X-XXXXX-XX-X/XX/XX ...\$15.00. phone is connected to 12 of the nodes, providing free internal Voice over Internet Protocol (VoIP) calls. Internal call usage has been more sporadic than envisioned due to the inability to call mobile phones and landlines. Since breakout (and in) was technically feasible, a plan was devised to cover the costs and provide the breakout service legally. Revenues come from two sources. Firstly, since June 2013, more than 1000 USD has been collected collectively by charging mobile phones using the spare capacity of the solar systems designed to power the routers. This revenue financed an Internet connection required to call mobile phones from the stations installed and cover the maintenance costs [8]. A second source of income is a prepaid fee to call mobile phones via a gateway, a service that has been active since September 2014. Plans are in place to provide Internet services and provide a third source of revenue to sustain the network.

The challenge is to provide these services legally so that the network can be financially sustainable. In this paper, we describe the regulatory framework in South Africa, and then how we went about making a community network legal within that framework. We detail the lessons learned so that others can base similar efforts on our experience.

\section{REGULATIONS IN SOUTH AFRICA}

\subsection{Electronic Communications}

The registration, transfer and granting of service licences and licence exemptions in South Africa is performed by the Independent Communications Authority of South Africa (ICASA) in accordance with the provisions of the Electronic Communications Act, 36 of 2005 (ECA) [9]. Recent amendments to the ECA have been introduced by the Electronic Communications Amendment Act, 1 of 2014 (ECAA)) [17]. According to ICASA, applications are processed in a period of 5-7 weeks after reception. In South Africa there are two categories of licenses regarding electronic communications:

- Electronic Communications Service (ECS) licences allow the holder to provide licensed services (such as the provision of voice and data services) to customers over its own or over another licensee's network.

- Electronic Communications Network Service (ECNS) licences allow the holder to establish and operate a network. ECNS licensees are also able to enter into commercial arrangements with other ECNS licensees in order for the former to benefit from the use of the network owned and operated by the latter. 
At the same time, both ECS and ECNS can be either Individual or Class. Individual ECNS (IECNS) are national in scope and Class (CECNS) are regional, e.g. District Municipality. The main difference between Individual and Class ECS (IECS and CECS, respectively) is the numbering: if one requires numbers ranging in accordance to the National Numbering Plan (NNP), one needs an IECS; otherwise, one requires a CECS. One can be exempted from holding an ECS license on the basis of [11]:

- A person or company who provides ECS on a nonprofit basis.

- A reseller who provides ECS duly obtained from another licensee.

- A person who provides an ancillary service: single or bundle of retail services which do not amount to an ECS and includes necessary but incidental elements of ECS, where such ECS elements do not constitute the major purpose, utility or value of the service, including but not limited to, tracking, alarm and similar services.

One can be exempted from an ECNS license based on [11]:

- A Small Electronic Communications Network (SECN) is a network that lies within a limited area, and is used by a specific user group (must use frequencies which are licence exempt).

- A Private Electronic Communications Network (PECN) is a network used primarily for providing electronic communications for the owner's own use [9]. Where a PECN resells, leases or otherwise makes available any spare capacity on its network to a third party, such resale, lease or other provisioning of spare capacity is subject to additional regulations.

\subsection{Radio Spectrum}

In addition to complying with the ECA and the ECAA, the use of radio spectrum is also regulated by ICASA. Most bands require a license, but as in many other countries, networks operating in Industrial Scientific and Medical (ISM) bands are exempted from a licence. Although some manufacturers are producing equipment in $900 \mathrm{MHz}$ and $17 \mathrm{GHz}$ ISM bands that are exempted, in this document we will focus on the ones that are defined in the 802.11 standard[1]. However, use and possession of all forms of radio apparatus that operate in those bands must still comply with the following requirements [14]:

- Each radio apparatus must be type-approved by ICASA

- The technical characteristics of type-approved devices (frequencies, transmit power and external high-gain antenna) must not be altered without a new type approval certificate issued by ICASA.

- The devices must be operated within and not exceed, the technical parameters set out by ICASA. In the regulations for the 802.11 bands the more relevant parameters, i.e. the Equivalent Isotropic Radiated Power (EIRP) and the topology to which they apply, e.g. Point to Point (PtP) or Point to Multipoint (PtMP), are presented in Table 1.

\begin{tabular}{|l|l|l|l|}
\hline Band $(\mathrm{MHz})$ & Tx Power & EIRP & Link Topology \\
\hline $2400-2483.5$ & n. d. & $20 \mathrm{dBm}$ & PtP, PtMP \\
\hline $5150-5350$ & n. d. & $23 \mathrm{dBm}$ & PtMP \\
\hline $5470-5725$ & n. d. & $30 \mathrm{dBm}$ & PtMP \\
\hline $5725-5850$ & n. d. & $36 \mathrm{dBm}$ & PtP, PtMP \\
\hline $5725-5850[12]$ & 1 W & $53 \mathrm{dBm}$ & PtP \\
\hline
\end{tabular}

Table 1: Regulation of $\mathbf{8 0 2 . 1 1}$ bands in South Africa.

- The antenna must always be used at the lowest average height where the device will still work effectively.

- The user must operate in a secondary basis, i.e. must not cause interference on another licence holder.

- The user will receive zero protection from interference from the Authority.

\subsection{Co-Operatives}

Registration, operation and management of co-operatives is performed by the Companies and Intellectual Property commission (CIPRO) in accordance with the provisions of the Co-Operatives Act, 14 of 2005 (CA) [6]. Recent amendments to the CA have been introduced by the Co-Operatives Amendment Act, 1 of 2014 (CAA) [15]. On its website, CIPRO states that an application will be processed within 10 days after the application has been lodged.

In the act, co-operatives are defined in layers. A primary co-operative is defined as "a co-operative formed by a minimum of five natural persons whose object is to provide employment or services to its members and to facilitate" [6]. A secondary co-operative means "a co-operative formed by two or more primary co-operatives to provide sectoral services to its members, and may include juristic persons" [6]. Among the different types of co-operatives defined, the CA defines the possibility of co-operatives to be not-for-profit as a social co-operative which appears as "a non-profit cooperative which engages in the provision of social services to its members" [6].

Additionally, the CAA introduced categorization for primary co-operatives [15]: A, B and C, depending on their size. There is no explicit definition of the size apart from small, medium and big. For category A, the amendment says "Category A primary co-operatives must produce an annual report which does not have to be audited or independently reviewed, to the registrar in respect of each financial year, signed by the directors of the co-operative." [15].

\subsection{Application process and fees}

In this subsection, we focus on Class licences. A local telco does not intend to cover a national area, so it does not require an IECNS. It does not require an IECS either, because it is not required to use numbers from the NNP. The registration of each ECS and ECNS licence required has an initial registration fee of 1000 USD, e.g. if both are needed then the fees total 2000 USD. There is also a renewal renovation fee of 500 USD after 10 years. If one builds infrastructure in two different municipal districts, then two different CECNS are required [16].

Additionally, if any of the licenses generate revenue, the holder needs to pay an annual fee. The contribution is a factor of the revenue obtained by the holder. For the lowest 
group ( $0-5.000 .000$ USD), which is the most likely for a local telco, the annual fee is $0.15 \%$ of that revenue [16].

If exempted from holding a license, one is exempted to pay registration, renewal and annual fees. Instructions and forms in can be found in [13]. In the case of the telco being constituted as a co-operative, the instructions and forms are included in [10]. The cost of registering one is almost negligible, less than 30 USD.

\section{PROCESS FOLLOWED}

\subsection{Zenzeleni Networks Ltd}

In order to be able to fit within the ECA requirements, an entity that could apply for the licences described above needed to be set up. The community in Mankosi gave the mandate to do so to a committee comprised a member from each household hosting an analogue phone, some of them Tribal Authority members. This committee decided that they wanted to organize themselves as a co-operative as they had received already information from the Local Municipality of its benefit and the potential support they could be provided. An application to register the "non-specific" cooperative, Zenzeleni Networks Ltd, was submitted on the 21 January 2014. In the cover letter of the application, it was argued that Zenzeleni would fit in Category A of the forthcoming CAA.

Zenzeleni Networks Ltd was officially registered on 5 February 2014, although the certification did not arrive to the chairperson until 26 March. These are the three goals of the co-operative registered:

1. To provide telecommunication services (voice and data) to its members on a not-for-profit basis. The co-operative will negotiate wholesale prices with Internet Service Providers (ISPs) and will maintain and operate a telecommunication network deployed in Mankosi Administrative Area (AA) to reduce the cost of communications amongst its members.

2. To reinvest the surplus generated by its activities in initiatives aiming at the upliftment of its members, the cooperative will, once a year, select local development initiatives proposed by its members which will receive funding for its start-up and/or expansion.

3. To operate and maintain solar charging stations to augment the financial sustainability of the telecommunication services. The co-operative will use existing solar power generation and storage systems, and will ensure the security and full charge of the devices.

\subsection{Licence exemptions}

Once the co-operative registration certificate was obtained, the paperwork for the exemption of the CECS and CECNS started. The application was submitted 10 April 2014. The exemption request for the CECS was done on the basis of constituting Zenzeleni Networks Ltd as a not-for-profit telecommunications cooperative. The request for ECNS exemption was done via presenting the co-operative as a PECN, i.e. "used primarily for providing electronic communications for the owner's own use". For this to work, users of the network need to become cooperative members; so users are owners, as in most community networks. The licence exemption for both was received on 10 September 2014.

\section{LESSONS LEARNED}

\subsection{Radio Regulations Compliance}

Currently, Zenzeleni is not complying with two of the requirements for operating in licence exempted bands:

- No modification of type-approved devices. The Mesh Potato is type-approved but in order to extend the range of each access point, an external antenna was attached to them, which is not type-approved.

- Maximum EIRP. Combined, the Mesh Potato and the antenna use a EIRP of $28 \mathrm{dBm}$ instead of the $20 \mathrm{dBm}$ allowed for the $2.4 \mathrm{GHz}$ band.

However, it is possible to overcome these two issues by deploying the mesh in the $5 \mathrm{GHz}$ band instead of at 2.4 GHz. Operating in higher frequencies increases the attenuation that the signal suffers when travelling through open space. In the bands allowed for $\mathrm{WiFi}$, the path loss is $7 \mathrm{dBm}$ higher in $5 \mathrm{GHz}$ than in $2.4 \mathrm{GHz}$. As operation in the band $5725-5850 \mathrm{MHz}$ allows for $36 \mathrm{dBm}$, type-approved devices allowing such an EIRP would have a similar effect to the ones currently installed $(28 \mathrm{dBm}+7 \mathrm{dBm})$, yet be able to adhere to the regulatory framework. These devices do exist and are type-approved and available in the South African market ${ }^{1}$. Zenzeleni is now working on this solution.

\subsection{Challenges to the process}

Although Zenzeleni achieved license exemption, it was not free of challenges. As there is no specific regulation for social co-operatives, and the regulations for Category A primary co-operatives were not available at the time of application, we were told by CIPRO to use generic forms and either remove parts or leave empty those which did not apply. It was done as told, but when the documents need to be certified by a Commissioner of Oath, he rejected signing a document with empty sections. It was required to put in contact both institutions for the commissioner to unblock the process.

More than 6 weeks transpired between the time when the co-operative was registered and when the registration certificate was received by the co-operative. People in Mankosi do not have a postal address and everyone shares one from the local store. However, the store's postal address is not physically in Mankosi either, and is a post box in Ngqeleni, a town $50 \mathrm{~km}$ away. Additionally, the store is $10 \mathrm{~km}$ from the co-operative's chairperson's house, who relies on a letter to be forwarded to one of his relatives at a nearby school.

These 6 weeks of delay are small compared to the delay experienced with ICASA. Initially, a backlog in processing applications was provided as a reason; but then applications lodged after Zenzeleni's application started to be resolved. We suspect the application was delayed due to its novelty and as in the previous case of submitting paperwork for the co-operative, it required personal interventions to unblock the process. We believe that once the precedent has been set, similar cases should not experiment the same delays.

\subsection{Positive side effects}

The model presented in this paper positively sets a precedent for similar bottom-up initiatives in South Africa and elsewhere. The fact that the co-operative registered is notfor-profit means that all the profit (if any) after the costs of

\footnotetext{
${ }^{1}$ http://www.ubnt.com/airmax/airmax-omni-antenna
} 
operating and maintaining the network (salaries included, if any) does not go to the shareholders, but is invested back into the community to achieve the co-operative's goals.

When registering the cooperative we argued that Zenzeleni belonged to Category A. Although specifications are still not in place, if this argument is accepted, the cooperative need not audit accounts, thus saving the cost of auditors.

The co-operative model additionally allows for the federation of primary co-operatives into secondary level ones. Currently, Zenzeleni cannot provide services to another community. Other communities could replicate the model presented here and then federate themselves into a secondary co-operative that could be granted a similar exemption as the primary (not-for-profit, PECN). This would follow a similar structure used by indigenous communities in Canada [3], where a second level institution provides the services that primary co-operatives cannot provide for themselves e.g. technical expertise, aggregating demand, and advocacy.

Having the exemptions granted by ICASA has many positive sides effects apart from the obvious one of adhering to the South African regulatory framework and thereby avoiding prosecution. Licence exemption holders need not pay the registration fee, thus saving 2000 USD initial license fees (for ECS and ECNS) which is twice the money collected thus far in a year by the Zenzeleni for charging mobile phones. Additionally, Zenzeleni does not need to pay an annual percentage of the revenue obtained or the audit to calculate the fee. Avoiding these fees has direct economic benefits, and also reduces the management burden as the holder does not have to produce additional documentation. This benefits the exemption holder and the regulator, too [18].

Furthermore, it allows co-location of equipment in an incumbent's towers (paying a fee), something they allow to licence holders only ${ }^{2}$. This could eventually allow to access a much faster and cheaper Internet connection than the one available in our rural area. There is a quite a large capillarity in nearby towers. Give the footprint of Zenzeleni's coverage, three are different ones in the area. Given the $200 \mathrm{~W}$ EIRP allowed in the $5.8 \mathrm{GHz}$ band, relays could be co-located in towers to reach an even cheaper Internet connection.

These positive side effects can apply to other community networks using WiFi in South Africa, and to those using other technologies as the CECS and CECNS licence exemptions obtained are technology agnostic. Thus, if regulations about TV White spaces, or the more recent GSM White Spaces [2], include licence exemption to use additional radio spectrum on a secondary basis, they could use the model presented here in a straighforward manner. Additionally, it could be used in countries with a similar regulatory model to South Africa, like Namibia [5].

\section{ACKNOWLEDGMENTS}

Thanks to S. Song who put us in contact with Ellipsis, and D. Carman, who suggested we look at constituting a not-for-profit co-operative. Thanks to Transcape for allowing to use their facility to process applications, and to Zenzeleni members for their resolution and patience, especially M.J. Siya. We also thank Telkom, Cisco, Aria Technologies and THRIP (Technology and Human Resources for Industry Partnership) for their financial support via the Telkom Cen- tre of Excellence (CoE) programme (NRF reference number (UID) 75191). Lastly, this work is also supported by the CONFINE Integrated Project FIRE \#288535.

\section{REFERENCES}

[1] H. Galperin and F. Bar. The microtelco opportunity: evidence from Latin America. ITID, 3(2):73-86, 2006.

[2] S. Hasan, K. Heimerl, K. Harrison, K. Ali, S. Roberts, A. Sahai, and E. Brewer. Gsm whitespaces: An opportunity for rural cellular service. In IEEE DySPAN, 2014.

[3] R. McMahon, M. Gurstein, B. Beaton, S. O'Donnell, and T. Whiteducke. Making Information Technologies Work at the end of the Road. Journal of Information Policy, 4:250-269, 2014.

[4] C. Pade, B. Mallinson, and D. Sewry. An elaboration of critical success factors for rural ICT project sustainability in developing countries: Exploring the Dwesa case. The Journal of Information Technology Case and Application, 10(4):32-55, 2008.

[5] Republic of Namibia. Communications Act. Namibian Government Gazette, (4378), 2009.

[6] Republic of South Africa (RSA). Co-operatives Act. South African Government Gazette, 482(27912), 2005.

[7] C. Rey-Moreno, Z. Roro, W. D. Tucker, M. J. Siya, N. J. Bidwell, and J. Simo-Reigadas. Experiences, challenges and lessons from rolling out a rural WiFi mesh network. In Proc. 3rd ACM DEV, 2013.

[8] C. Rey-Moreno, M. Ufitamahoro, I. Venter, and T. W.D. Co-designing a Billing System for Voice Services in Rural South Africa: Lessons Learned. In Proc. 5th ACM DEV, 2014.

[9] RSA. Electronic Communications Act. South African Government Gazette, 490(28743), 2006.

[10] RSA. Regulations Under the Co-Operative Act 2005). South African Government Gazette, (29830), 2007.

[11] RSA. Regulations Regarding License Exempt Electronic Communication Networks. South African Government Gazette, (31289), 2008.

[12] RSA. ICASA's decision on the use of the 5725-5850MHz. South African Government Gazette, 534(32729), 2009.

[13] RSA. Licensing Processes and Procedures Amendment Regulations). South African Government Gazette, 540(33297), 2010.

[14] RSA. Final Radio Frequency Spectrum Regulations. South African Government Gazette, 549(34172), 2011.

[15] RSA. Co-operatives Amendment Act. South African Government Gazette, 578(36729), 2013.

[16] RSA. Electronic Communications Act (36/05): General Licence Fees Regulation, 2012. South African Government Gazette, 573(36323), 2013.

[17] RSA. Electronic Communications Amendment Act. South African Government Gazette, 586(37536), 2014.

[18] A. Van Gorp and C. Morris. Serving under-serviced areas in South Africa: the potential for Wi-Fi community network deployment and the role of regulation. info, 10(1):65-78, 2008.

\footnotetext{
${ }^{2}$ http://www.telkom.co.za/wholesale-web/products-andservices/co-location.jsp
} 